Article

\title{
Impact of Lower Screening TSH Cutoff Level on the Increasing Prevalence of Congenital Hypothyroidism
}

\author{
Violeta Anastasovska ${ }^{1, *}$ and Mirjana Kocova ${ }^{2}$ \\ 1 Laboratory for Neonatal Thyroid Screening, University Pediatric Clinic, Medical Faculty, \\ Skopje 1000, Macedonia \\ 2 Department of Endocrinology and Genetics, University Pediatric Clinic, Medical Faculty, \\ Skopje 1000, Macedonia; mirjanakcova@yahoo.com \\ * Correspondence: violeta_anastasovska@yahoo.com; Tel.: +389-75-500-542; Fax: +389-2-3129-027
}

Academic Editor: Harvey Levy

Received: 7 February 2017; Accepted: 30 March 2017; Published: 4 April 2017

\begin{abstract}
Lower cutoff levels in screening programs have led to an increase in the proportion of detected cases of transient hypothyroidism, leading to an increase in the overall prevalence of primary congenital hypothyroidism $(\mathrm{CH})$ in several countries. We have performed a retrospective evaluation on the data from $251,008(96.72 \%)$ neonates screened for thyroid-stimulating hormone (TSH) level in dried blood spot specimens taken $48 \mathrm{~h}$ after birth, between 2002 and 2015, using the DELFIA method. A TSH value of $15 \mathrm{mIU} / \mathrm{L}$ whole blood was used as the cutoff point until 2010 and $10 \mathrm{mIU} / \mathrm{L}$ thereafter. Primary $\mathrm{CH}$ was detected in 127 newborns $(1 / 1976)$ of which $81.1 \%$ had permanent and $18.9 \%$ had transient $\mathrm{CH}$. The prevalence of primary $\mathrm{CH}$ increased from $1 / 2489$ before 2010 to $1 / 1585$ thereafter $(p=0.131)$. However, the prevalence of permanent $\mathrm{CH}$ increased only slightly $(p=0.922)$, while the transient $\mathrm{CH}$ prevalence showed an 8 -fold increase after lowering the TSH cutoff level $(p<0.001)$. In cases of permanent $\mathrm{CH}$, we observed a lower prevalence of thyroid dysgenesis $(82.7 \%$ vs. $66.7 \%)$ and a higher prevalence of a normal in situ thyroid gland $(17.3 \%$ vs. $33.3 \%)$, for the period with a lower TSH cutoff value. Our findings support the impact of a lower TSH cutoff on the increasing prevalence of congenital hypothyroidism.
\end{abstract}

Keywords: congenital hypothyroidism; prevalence; neonatal screening; thyroid-stimulating hormone; cutoff level

\section{Introduction}

A reliable primary congenital hypothyroidism $(\mathrm{CH})$ prevalence of $1 / 3000-1 / 4000$ was reported when neonatal screening for $\mathrm{CH}$ was first introduced [1]. Over the past two decades, a higher prevalence of $\mathrm{CH}$ has been identified worldwide ranging from $1 / 1600$ to $1 / 2800$ live births [2-5]. Potential causes include environmental factors, changes in the ethnic composition of the population, modification of the screening program methodology and application of the lower thyroid-stimulating hormone (TSH) cutoff level at screening [5-8]. The shift from primary T4 to primary TSH screening strategies, and the lowering of the TSH cutoff levels have been attributed to the increasing $\mathrm{CH}$ prevalence worldwide, probably due to more frequent detection of the milder forms of $\mathrm{CH}$. The majority of cases detected using a lower TSH cutoff tend to have milder hypothyroidism, with imaging often demonstrating an eutopic, "gland in situ". However, some cases turn out to have transient $\mathrm{CH}[5,7,9-11]$.

The aim of this study was to investigate the influence of a lower TSH cutoff level on the prevalence of $\mathrm{CH}$ as well as on the prevalence trend of different etiologies of $\mathrm{CH}$. 


\section{Materials and Methods}

CH screening has been mandatory in Macedonia since 2007, after a previous 5 year pilot study. There is a centralized screening center located at the University Pediatric Clinic in the capital of Macedonia with screening coverage of over $95 \%$ of the total neonatal population. The DELFIA method with the neonatal TSH kit (DELFIA, Perkin-Elmer, WallacOy, Turku, Finland) is used to measure the whole-blood thyroid-stimulating hormone (TSH) level as a primary screening test, as described previously [12]. Heel prick whole-blood samples were taken on filter paper Schleicher and Schuell Inc., Keene, NH, USA (Whatman 903), between 48 and $72 \mathrm{~h}$ of life. Preterm newborns ( $<37$ weeks' gestation), babies with low birth weight $(<2500 \mathrm{~g})$, and sick newborns with a prolonged stay in the neonatal intensive care units were re-sampled two weeks after the first screening. Neonates who were discharged from the maternity hospital before $48 \mathrm{~h}$ of life were screened at the moment of discharge. A 14-year retrospective population-based study was performed on a total of 251,008 (96.72\%) newborns, screened in the period between April 2002 and December 2015. A TSH value of $15 \mathrm{mIU} / \mathrm{L}$ whole blood was used as the cutoff until 2010 (period 1), and $10 \mathrm{mIU} / \mathrm{L}$ from 2011 onward (period 2). A total of 136,874 (54.5\%) newborns were screened during period 1, and 114,134 (45.5\%) during period 2. The indications for biochemical and clinical evaluation as well as the performed analysis to complete the $\mathrm{CH}$ diagnosis were described previously $[13,14]$. Neonates with a persistent deficiency of the thyroid hormone that requires life-long treatment were classified as babies with permanent $\mathrm{CH}$. Transient $\mathrm{CH}$ was diagnosed whenever thyroid hormone levels returned to normal, after tapering down and discontinuation of the thyroxine therapy $[15,16]$. Newborns detected with $\mathrm{CH}$ underwent thyroid ultrasonography followed by scintigraphy.

Statistical analysis was done with Statistical Package for Social Sciences (version 20.0; SPSS Inc., Chicago, IL, USA). Descriptive analysis was performed on the obtained TSH/T4 values. Pearson $\chi^{2}$ was used for the comparison of proportions, and statistical significance was set at $p<0.05$.

The study was approved by Human Research Ethics Committees of University Pediatric Clinic, Medical Faculty, Skopje, and the the Local Ethics Committee. The authors declare that all investigations were carried out following the rules of the Declaration of Helsinki of 1975 and its later amendments. For this retrospective type of study, formal consent is not required.

\section{Results}

During the period 2002-2015, primary congenital hypothyroidism was detected in 127 newborns with an overall prevalence of $1 / 1976$, and a female to male ratio of 1.35:1. Among neonates with primary $\mathrm{CH}, 103(81.1 \%)$ had permanent $\mathrm{CH}$, indicating a prevalence of $1 / 2437$ and female predominance (female to male ratio 1.71:1) and $24(18.9 \%)$ had transient $\mathrm{CH}$ with a prevalence of 1/10,459 and male predominance (female to male ratio 1:2), Table 1.

Table 1. Impact of a lower thyroid-stimulating hormone (TSH) cutoff level on the congenital hypothyroidism $(\mathrm{CH})$ prevalence.

\begin{tabular}{ccccc}
\hline & \multicolumn{4}{c}{ Prevalence of CH $(n)$} \\
\cline { 2 - 5 } & Total & Period 1 & Period 2 & $p$ Value \\
\hline Primary CH & $1 / 1976(127)$ & $1 / 2489(55)$ & $1 / 1585(72)$ & 0.131 \\
Permanent CH & $1 / 2437(103)$ & $1 / 2632(52)$ & $1 / 2238(51)$ & 0.922 \\
Transient CH & $1 / 10,459(24)$ & $1 / 45,625(3)$ & $1 / 5435(21)$ & $<0.001$ \\
\hline Number of screened newborns & 251,008 & $136,874(54.5 \%)$ & $114,134(45.5 \%)$ \\
\hline
\end{tabular}

The prevalence of primary $\mathrm{CH}$ confirmed at birth increased from 1/2489 live births in period 1 to $1 / 1585$ in period 2 with an increment of $36.3 \%\left(p=0.131 ; \chi^{2}=2.276\right)$, and the prevalence of permanent $\mathrm{CH}$ increased from $1 / 2632$ to $1 / 2238$ live births with an increment of $15 \%(p=0.922$; $\chi^{2}=0.10$ ) - both statistically non-significant. On the other hand, we revealed a significant, more than 
8 -fold increase in the prevalence of transient $\mathrm{CH}$, from $1 / 45,625$ live births in period 1 to $1 / 5435$ in period $2\left(p<0.001 ; \chi^{2}=13.50\right)$, as shown in Table 1 . The percentage of transient $\mathrm{CH}$, among children with $\mathrm{CH}$, was significantly higher in period $2(29.2 \%)$ than in period $1(5.5 \%),(p<0.001)$.

We also evaluated the impact of lowering the TSH cutoff value on the prevalence trend of permanent $\mathrm{CH}$ caused by different etiologies, obtained with thyroid ultrasonography and/or scintigraphy. Thus, we observed a slightly lower prevalence of thyroid dysgenesis (athyreosis, ectopic gland, hemiagenesis, and hypoplasia in situ) in period $2(66.7 \%)$ than in period $1(82.7 \%)$, a decrement of 5.2\%; and a higher prevalence of a normal in situ thyroid gland in period $2(33.3 \%)$ compared to period $1(17.3 \%)$, an increment of $55.9 \%$; however, both are statistically non-significant (Table 2).

Table 2. Prevalence trend of permanent $\mathrm{CH}$ with different underlying etiologies.

\begin{tabular}{cccc}
\hline & \multicolumn{3}{c}{ Prevalence of Permanent CH $(\boldsymbol{n})$} \\
\cline { 2 - 4 } & Period 1 $(\boldsymbol{n = 5 2 )}$ & Period 2 $(\boldsymbol{n = 5 1 )}$ & $\boldsymbol{p}$ Value \\
\hline Thyroid dysgenesis & $1 / 3183(43)$ & $1 / 3357(34)$ & 0.305 \\
Normal/hyperplastic thyroid & $1 / 15,208(9)$ & $1 / 6714(17)$ & 0.117 \\
\hline
\end{tabular}

\section{Discussion}

Over the years, lower TSH cutoffs have been adopted in some neonatal thyroid screening programs worldwide, leading to a progressive increase in the detection of additional mild forms of the disease and with that an increase in the overall prevalence of $\mathrm{CH}[3,7]$. Our 14-year retrospective study showed a higher prevalence of $\mathrm{CH}$ confirmed at birth in Macedonia $(1 / 1976)$ than previously reported (1/2591) -an increment of $23.7 \%$ [12]. In fact, the higher prevalence of $\mathrm{CH}$ was observed over period 2, thus indicating the impact of lowering the TSH cutoff level on the overall $\mathrm{CH}$ prevalence. Specifically, the prevalence of primary $\mathrm{CH}$ confirmed at birth increased from $1 / 2489$ live births in period 1 to $1 / 1585$ in period 2 (an increment of 36.3\%). The latter is higher than the prevalence reported in Italy $(1 / 1940)$ [6], Greece $(1 / 1749)$ [3], and Serbia (1/1872) [17] for the period of lower TSH cutoff thresholds but lower than that reported in Turkey (1/650) [18]. However, a two-fold increase in the prevalence of $\mathrm{CH}$ has been reported by six Newborn Screening Programs around the world, after lowering the TSH cutoff [9]. In Iran, where the TSH cutoff is $5 \mathrm{mIU} / \mathrm{L}$ whole blood, the estimated birth prevalence of $\mathrm{CH}$ is as high as $1 / 307$ live births [19].

In the present study, the prevalence of permanent $\mathrm{CH}$ showed an increment of $15 \%$ for period 2 $(1 / 2238)$, (Table 1$)$, which is within the range of $\mathrm{CH}$ prevalence rates reported in the literature $(1 / 1600-1 / 2800)$ [2-5]. However, it was not in accordance with some reports stating that transient and permanent forms of $\mathrm{CH}$ have contributed jointly to the increased $\mathrm{CH}$ prevalence [10]. The increased prevalence of $\mathrm{CH}$ after reducing the cutoff point is not necessarily a single predictor of transient TSH elevation [3], but in our case the prevalence of transient $\mathrm{CH}$ increased more than 8-fold. Similarly, an approximate 5 -fold increase in the prevalence of transient $\mathrm{CH}$ has been reported in Turkey after reducing the cutoff point $(1 / 1154$ vs. 1/6202) $[10,20]$. The percentage of transient $\mathrm{CH}$ within the entire $\mathrm{CH}$ group revealed in our study showed an increment from $5.5 \%$ of all $\mathrm{CH}$ to $29.2 \%$, indicating the important contribution of the lower TSH cutoff level in detecting additional cases of transient $\mathrm{CH}$. This rate is much higher than the expected rate of $5-10 \%$ reported for iodine-sufficient populations [21,22]. A significant increase in the transient $\mathrm{CH}$ from none in the first period $(30 \mathrm{mIU} / \mathrm{L}$ whole blood cutoff) to $35 \%$ of all $\mathrm{CH}$ patients in the last period (9 mIU/L whole blood cutoff), was recently reported in central Serbia with 30 years of experience in thyroid screening [17]. A similar finding was reported from Italy, for a period of 20 years [6]. Kara et al. revealed an increased rate of transient CH to $35 \%$ in 2008 (10 mIU/L whole blood cutoff) and 56\% in 2009-2010 (7.5 mIU/L whole blood cutoff), compared to $27 \%$ in the period 2000-2002 (20 mIU/L whole blood cutoff) [10]. In general, lower cutoff levels in screening programs have led to an increase in the proportion of detected cases of 
transient hypothyroidism, leading to an increase in the overall prevalence of primary $\mathrm{CH}$. Whether early detected mild $\mathrm{CH}$ cases by newborn screening can benefit from early thyroid hormone treatment is still controversial [23]. Some authors have reported that it may have beneficial effects on the full brain function of the affected children [24-27]. With this in mind, we believe that a TSH cutoff value of $10 \mathrm{mIU} / \mathrm{L}$ whole blood is acceptable. Further lowering of the cutoff value should be postponed until clear data on the benefits for children versus family anxiety and additional cost are assessed by large international studies.

Another purpose of this study was to evaluate the impact of a reduced TSH cutoff point on the prevalence rate of permanent $\mathrm{CH}$ with different underlying causes. A lower rate of thyroid dysgenesis and higher proportion of a normal in situ thyroid gland were observed among children with permanent $\mathrm{CH}$ in period 2 compared to period 1 , although the difference did not reach statistical significance. In Italy, a significant increase in permanent $\mathrm{CH}$ with normal in situ thyroid for the period with reduced TSH cutoff compared to the previous one has been reported [6]. Corbetta et al. reported a higher rate of newborns with a normally located thyroid gland which represents two-thirds of the overall $\mathrm{CH}$ population [7]. In Canada, Deladoey et al. found that lowering the cutoff point resulted in identifying more mild $\mathrm{CH}$ forms with a normally located thyroid gland [28].

Lowering the TSH cutoff is an important factor contributing to the higher prevalence of primary $\mathrm{CH}$ in Macedonia and, our results show a significant impact of transient $\mathrm{CH}$ on the increased prevalence of primary $\mathrm{CH}$ in the country. Further analysis is necessary to identify the other environmental and genetic factors associated with the occurrence of transient $\mathrm{CH}$ in our population.

Author Contributions: Both authors have contributed to the critical revision of the manuscript for important intellectual content. Violeta Anastasovska carried out the thyroid screening in the country, and contributed to the retrospective evaluation of the data, idea and concept of the manuscript as well as designing, writing and editing the manuscript. Mirjana Kocova contributed to diagnosis, ultrasound check-ups, treatment and follow-up of the patients with congenital hypothyroidism as well as designing and editing the manuscript.

Conflicts of Interest: The authors declare no conflict of interest. Both authors have reviewed the manuscript and agree to its submission and format.

\section{References}

1. Fisher, D.A.; Dussault, J.H.; Foley, T.P., Jr.; Klein, A.H.; LaFranchi, S.; Larsen, P.R.; Mitchell, M.L.; Murphey, M.H.; Walfish, P.G. Screening for congenital hypothyroidism: Results of screening one million North American infants. J. Pediatr. 1979, 94, 700-705. [CrossRef]

2. Albert, B.B.; Cutfield, W.S.; Webster, D.; Carll, J.; Derraik, J.G.B.; Jefferies, C.; Alistair, J.; Gunn, A.J.; Hofman, P.L. Etiology of increasing incidence of congenital hypothyroidism in New Zealand from 1993-2010. J. Clin. Endocrinol. Metab. 2012, 97, 3155-3160. [CrossRef] [PubMed]

3. Mengreli, C.; Kanaka-Gantenbein, C.; Girginoudis, P.; Magiakou, M.A.; Christakopoulou, I.; Giannoulia-Karantana, A.; Chrousos, G.P.; Dacou-Voutetakis, C. Screening for congenital hypothyroidism: The significance of threshold limit in false-negative results. J. Clin. Endocrinol. Metab. 2010, 95, 4283-4290. [CrossRef] [PubMed]

4. Harris, K.B.; Pass, K.A. Increase in congenital hypothyroidism in New York State and in the United States. Mol. Genet. Metab. 2007, 91, 268-277. [CrossRef] [PubMed]

5. Hetzberg, V.; Mei, J.; Therrell, B.L. Effect of laboratory practices on the incidence rate of congenital hypothyroidism. Pediatrics 2010, 125, S48-S53. [CrossRef] [PubMed]

6. Olivieri, A.; Fazzini, C.; Medda, E. Multiple factors influencing the incidence of congenital hypothyroidism detected by neonatal screening. Horm. Res. Paediatr. 2015, 83, 86-93. [CrossRef] [PubMed]

7. Corbetta, C.; Weber, G.; Cortinovis, F.; Calebiro, D.; Passoni, A.; Vigone, M.C.; Beck-Peccoz, P.; Chiumello, G.; Persani, L. A 7-year experience with low blood TSH cutoff levels for neonatal screening reveals an unsuspected frequency of congenital hypothyroidism (CH). Clin. Endocrinol. 2009, 71, 739-745. [CrossRef] [PubMed]

8. Kaiserman, I.; Maytal, A.; Siebner, R.; Sack, J. Effects of immigration on the incidence of congenital hypothyroidism. Eur. J. Endocrinol. 1997, 137, 356-359. [CrossRef] [PubMed] 
9. Ford, G.; LaFranchi, S. Screening for congenital hypothyroidism: A worldwide view of strategies. Best Pract. Res. Clin. Endocrinol. Metab. 2014, 28, 175-187. [CrossRef] [PubMed]

10. Kara, C.; Gunindi, F.; Yılmaz, G.C.; Aydın, M. Transient congenital hypothyroidism in Turkey: An analysis on frequency and natural course. J. Clin. Res. Pediatr. Endocrinol. 2016, 8, 170-179. [CrossRef] [PubMed]

11. Parks, J.S.; Lin, M.; Grosse, S.D.; Hintonn, C.F.; Drummond-Borg, M.; Borgfeld, L.; Sullivan, K.M. The impact of transient hypothyroidism on the increasing rate of congenital hypothyroidism in the United States. Pediatrics 2010, 125, S54-S63. [CrossRef] [PubMed]

12. Kocova, M.; Anastasovska, V.; Sukarova-Angelovska, E.; Tanaskoska, M.; Taseva, E. Clinical practice: Experience with newborn screening for congenital hypothyroidism in the Republic of Macedonia-A multiethnic country. Eur. J. Pediatr. 2015, 174, 443-448. [CrossRef] [PubMed]

13. Anastasovska, V.; Kocova, M. Ethnicity and incidence of congenital hypothyroidism in the capital of Macedonia. J. Pediatr. Endocrinol. Metab. 2016. [CrossRef] [PubMed]

14. Zdraveska, N.; Anastasovska, V.; Kocova, M. Frequency of thyroid status monitoring in the first year of life and predictors for more frequent monitoring in infants with congenital hypothyroidism. J. Pediatr. Endocrinol. Metab. 2016, 29, 795-800. [CrossRef] [PubMed]

15. Messina, M.F.; Aversa, T.; Salzano, G.; Zirilli, G.; Sferlazzas, C.; De Luca, F.; Lombardo, F. Early discrimination between transient and permanent congenital hypothyroidism in children with eutopic gland. Horm. Res. Paediatr. 2015, 84, 159-164. [CrossRef] [PubMed]

16. Rastogi, M.V.; LaFranchi, S.H. Congenital hypothyroidism. Orphanet J. Rare Dis. 2010, 5, 17. [CrossRef] [PubMed]

17. Mitrovic, K.; Vukovic, R.; Milenkovic, T.; Todorovic, S.; Radivojcevic, J.; Zdravkovic, D. Changes in the incidence and etiology of congenital hypothyroidism detected during 30 years of a screening program in central Serbia. Eur. J. Pediatr. 2016, 175, 253-259. [CrossRef] [PubMed]

18. Dilli, D.; Ozbaş, S.; Acıcan, D.; Yamak, N.; Ertek, M.; Dilmen, U. Establishment and development of a national newborn screening programme for congenital hypothyroidism in Turkey. J. Clin. Res. Pediatr. Endocrinol. 2013, 5, 73-79. [PubMed]

19. Dorreh, F.; Chaijan, P.Y.; Javaheri, J.; Zeinalzadeh, A.H. Epidemiology of congenital hypothyroidism in Markazi Province, Iran. J. Clin. Res. Pediatr. Endocrinol. 2014, 6, 105-110. [CrossRef] [PubMed]

20. Simsek, E.; Karabay, M.; Kocabay, K. Neonatal screening for congenital hypothyroidism in West Black Sea area, Turkey. Int. J. Clin. Pract. 2005, 59, 336-341. [CrossRef] [PubMed]

21. Fisher, D.A.; Grueters, A. Disorders of the thyroid in the newborn and infant. In Pediatric Endocrinology, 3rd ed.; Sperling, M.A., Ed.; Elsevier Saunders: Philadelphia, PA, USA, 2008; pp. 198-226.

22. Anastasovska, V.; Kocova, M. Newborn screening for thyroid-stimulating hormone as an indicator for assessment of iodine status in the Republic of Macedonia. J. Med. Biochem. 2016, 35, 1-5. [CrossRef]

23. Sağlam, H.; Buyukuysal, L.; Koksal, N.; Ercan, I.; Tarim, O. Increased incidence of congenital hypothyroidism due to iodine deficiency. Pediatr. Int. 2007, 49, 76-79. [CrossRef] [PubMed]

24. Rapaport, R. Congenital hypothyroidism: Expanding the spectrum. J. Pediatr. 2000, 136, 10-12. [CrossRef]

25. LaFranchi, S.H. Increasing incidence of congenital hypothyroidism: Some answers, more questions. J. Clin. Endocrinol. Metab. 2011, 96, 2395-2397. [CrossRef] [PubMed]

26. Cheetham, T. Congenital hypothyroidism: Managing the hinterland between fact and theory. Arch. Dis. Child. 2011, 96, 205. [CrossRef] [PubMed]

27. Ehrlich, R.M. Thyroxin dose for congenital hypothyoidism. Clin. Pediatr. (Phila) 1995, 34, 521-522. [CrossRef] [PubMed]

28. Deladoey, J.; Ruel, J.; Giguere, Y.; Van Vliet, G. Is the incidence of congenital hypothyroidism on the increasing really increasing? A 20-years retrospective population-based study in Quebec. J. Clin. Endocrinol. Metab. 2011, 96, 2422-2429. [CrossRef] [PubMed]

(C) 2017 by the authors. Licensee MDPI, Basel, Switzerland. This article is an open access article distributed under the terms and conditions of the Creative Commons Attribution (CC BY) license (http:/ / creativecommons.org/licenses/by/4.0/). 